Original Article

\title{
STRUCTURAL EXPLORATION AND PHARMACOPHORIC INVESTIGATION OF PYRAZOLE BASED ANALOGS AS NOVEL HISTONE DEACETYLASE 1 INHIBITOR USING COMBINATORIAL STUDIES
}

\section{AVINEESH SINGH, HARISH RAJAK ${ }^{*}$}

Medicinal Chemistry Research Laboratory, SLT Institute of Pharmaceutical Sciences, Guru Ghasidas University, Bilaspur 495009, (C. G.) India

Email: harishdops@yahoo.co.in

Received: 22 Sep 2017 Revised and Accepted: 22 Jan 2018

\section{ABSTRACT}

Objective: Histone deacetylase inhibitors (HDACi) have four essential pharmacophores as cap group, connecting unit, a linker moiety and zinc binding group for their anticancer and histone deacetylase (HDAC) inhibition activity. On the basis of this fact, the objective of this research was to evaluate the exact role of pyrazole nucleus as connecting unit and its role in the development of newer HDACi.

Methods: Ligand and structure-based computer-aided drug design strategies such as pharmacophore and atom based 3D QSAR modelling, molecular docking and energetic based pharmacophore mapping have been frequently applied to design newer analogs in a precise manner. Herein, we have applied these combinatorial approaches to develop the structure-activity correlation among novel pyrazole-based derivatives.

Results: the Pharmacophore-based 3D-QSAR model was developed employing Phase module and e-pharmacophore on compound 1. This 3D-QSAR model provides fruitful information regarding favourable and unfavourable substitution on pyrazole-based analogs for HDAC1 inhibition activity. Molecular docking studies indicated that all the pyrazole derivatives bind with HDAC1 proteins and showed critical hydrophobic interaction with 5ICN and 4BKX HDAC1 proteins.

Conclusion: The outcome of the present research work clearly indicated that pyrazole nucleus added an essential hydrophobic feature in cap group and could be employed to design the ligand molecules more accurately.

Keywords: 3D-QSAR, e-pharmacophore mapping, Ligand and structure-based designing, Docking, Pyrazole analogs

(C) 2018 The Authors. Published by Innovare Academic Sciences Pvt Ltd. This is an open access article under the CC BY license (http://creativecommons.org/licenses/by/4.0/) DOI: http://dx.doi.org/10.22159/ijpps.2018v10i3.22735

\section{INTRODUCTION}

Ligand and structure-based computer-aided drug design strategies includes several computational approaches that have been repeatedly applied to design and discover the new molecules. Practically, neither single ligand-based nor structure-based drug design strategy approach is unable to fulfil the needs of drug discovery and development [1-6]. Vorinostat (SAHA) (fig. 1) and other HDACi hamper different classes of histone deacetylases (HDACs) by interacting with the active pocket site of HDAC proteins leading to interfere with different tumor mediators. All these HDACi have four essential structural elements such as a surface recognition cap group, a connecting unit, a linker moiety and a zinc-binding domain (ZBD). The connection of aromatic cap group with linker

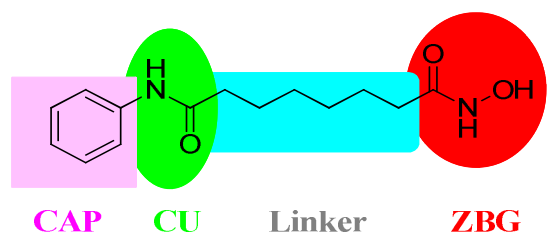

moiety in HDACi is essential for HDAC inhibitory activity [7, 8]. The substitution of amide connecting unit of SAHA with a heterocyclic nucleus has resulted in the development of SAHA like analogs. These substituted derivatives possess HDAC inhibitory activity against a variety of HDAC classes, indicating that heterocyclic nucleus as connecting unit retains the essential characteristic required for activity [9-15]. The key intention of the present study was to apply the structure and ligand-based tactics to recognize the importance of heterocyclic connecting unit at SAHA analogs. This study consists of numerous consecutive steps such as preparation of data set, the establishment of structure-activity relationship by 3D QSAR approach, molecular docking of ligands in the active site of a protein molecule, e-pharmacophore mapping and establishment of a correlation between structure and biological activity.

Fig. 1: Vorinostat (SAHA) and its pyrazole analogs

\section{MATERIALS AND METHODS}

\section{Biological data}

A set of 24 pyrazoles based SAHA analogs with HDAC1 inhibition activity was taken from literature to create biological dataset (table
1) as to determine the role of pyrazole nucleus as connecting unit in place of amide group in SAHA [16]. The dataset was collected from single laboratory report.

The $\mathrm{IC}_{50}$ value of analogs was transformed into negative logarithm of $\mathrm{IC}_{50}\left(\mathrm{pIC}_{50}\right)$ values by using formula, $\mathrm{pIC}_{50}=6-\log \mathrm{IC}_{50}(\mu \mathrm{m})$. 


\section{Ligand preparation}

The structures of pyrazole-based SAHA analogs were drawn using ChemDraw Ultra/Chem 3D software, cleaned, optimized and prepared using Ligprep v2.5 (Schrodinger, LLC, New York). This procedure basically involved various sequential steps such as preparation of 3D structures from 2D representation, development of ionization state at $\mathrm{pH} 7.0 \pm 2$, elimination of rebellious structures, generation of isomers, the addition of omitted hydrogen atoms and energy minimization by OPLS_2005 force field [17].

Table 1: Biological dataset of pyrazole-based SAHA analogs<smiles>[R3]c1c([R4])c([R2])c(Cn2ccc(CCCC(C)(C)C(=O)NO)n2)c([R6])c1[R6]</smiles>

\begin{tabular}{|c|c|c|c|c|c|c|c|c|}
\hline Comp. No. & $\mathbf{R}_{2}$ & $\mathbf{R}_{3}$ & $\mathbf{R}_{4}$ & $\mathbf{R}_{5}$ & $\mathbf{R}_{6}$ & $\mathbf{n}$ & $\begin{array}{l}\text { HDAC1 } \\
\mathrm{IC}_{50}(\mu \mathrm{m})\end{array}$ & $\mathrm{PIC}_{50}$ \\
\hline A-1 & $\mathrm{H}$ & $\mathrm{H}$ & $\mathrm{H}$ & $\mathrm{H}$ & $\mathrm{H}$ & 1 & 0.32 & 6.49 \\
\hline A-2 & $\mathrm{H}$ & $\mathrm{H}$ & $\mathrm{C}\left(\mathrm{CH}_{3}\right)_{3}$ & $\mathrm{H}$ & $\mathrm{H}$ & 1 & 1.31 & 5.88 \\
\hline$A-3$ & $\mathrm{H}$ & $\mathrm{H}$ & $\mathrm{CH}_{3}$ & $\mathrm{H}$ & $\mathrm{H}$ & 1 & 0.323 & 6.49 \\
\hline A- 4 & $\mathrm{H}$ & $\mathrm{H}$ & $\mathrm{Br}$ & $\mathrm{H}$ & $\mathrm{H}$ & 1 & 0.218 & 6.66 \\
\hline A-5 & $\mathrm{H}$ & $\mathrm{H}$ & $\mathrm{NO}_{2}$ & $\mathrm{H}$ & $\mathrm{H}$ & 1 & 0.242 & 6.62 \\
\hline A- 6 & $\mathrm{H}$ & $\mathrm{H}$ & $\mathrm{CF}_{3}$ & $\mathrm{H}$ & $\mathrm{H}$ & 1 & 0.197 & 6.71 \\
\hline A-7 & $\mathrm{H}$ & $\mathrm{H}$ & $\mathrm{F}$ & $\mathrm{H}$ & $\mathrm{H}$ & 1 & 0.293 & 6.53 \\
\hline A- 8 & $\mathrm{H}$ & $\mathrm{OCH}_{3}$ & $\mathrm{H}$ & $\mathrm{H}$ & $\mathrm{H}$ & 1 & 0.342 & 6.47 \\
\hline A-9 & $\mathrm{H}$ & $\mathrm{Br}$ & $\mathrm{H}$ & $\mathrm{H}$ & $\mathrm{H}$ & 1 & 0.068 & 7.17 \\
\hline A-10 & $\mathrm{H}$ & $\mathrm{Cl}$ & $\mathrm{F}$ & $\mathrm{H}$ & $\mathrm{H}$ & 1 & 0.116 & 6.94 \\
\hline A-11 & $\mathrm{F}$ & $\mathrm{H}$ & $\mathrm{F}$ & $\mathrm{H}$ & $\mathrm{H}$ & 1 & 0.539 & 6.27 \\
\hline A- 12 & $\mathrm{H}$ & $\mathrm{H}$ & $\mathrm{C}_{6} \mathrm{H}_{5}$ & $\mathrm{H}$ & $\mathrm{H}$ & 1 & 0.033 & 7.48 \\
\hline A-13 & $\mathrm{H}$ & $\mathrm{C}_{6} \mathrm{H}_{5}$ & $\mathrm{H}$ & $\mathrm{H}$ & $\mathrm{H}$ & 1 & 0.064 & 7.19 \\
\hline A-14 & $\mathrm{H}$ & $\mathrm{H}$ & & $\mathrm{H}$ & $\mathrm{H}$ & 1 & 0.376 & 6.42 \\
\hline A-15 & $\mathrm{H}$ & $\mathrm{H}$ & $\mathrm{C}_{6} \mathrm{H}_{5} \mathrm{CH}_{2} \mathrm{O}$ & $\mathrm{H}$ & $\mathrm{H}$ & 1 & 0.067 & 7.17 \\
\hline A-16 & $\mathrm{H}$ & $\mathrm{H}$ & $\mathrm{C}_{6} \mathrm{H}_{5} \mathrm{O}$ & $\mathrm{H}$ & $\mathrm{H}$ & 1 & 0.086 & 7.07 \\
\hline A- 17 & $\mathrm{H}$ & $\mathrm{H}$ & & $\mathrm{H}$ & $\mathrm{H}$ & 1 & 0.075 & 7.12 \\
\hline A-18 & $\mathrm{H}$ & $\mathrm{H}$ & $\mathrm{C}_{6} \mathrm{H}_{5} \mathrm{NH}$ & $\mathrm{H}$ & $\mathrm{H}$ & 1 & 0.035 & 7.46 \\
\hline A-19 & $\mathrm{H}$ & $\mathrm{C}_{6} \mathrm{H}_{5} \mathrm{NH}$ & $\mathrm{H}$ & $\mathrm{H}$ & $\mathrm{H}$ & 1 & 0.145 & 6.84 \\
\hline A-20 & $\mathrm{H}$ & $\mathrm{C}_{6} \mathrm{H}_{5} \mathrm{O}$ & $\mathrm{H}$ & $\mathrm{H}$ & $\mathrm{H}$ & 1 & 0.719 & 6.14 \\
\hline A- 21 & $\mathrm{H}$ & $\mathrm{H}$ & $\mathrm{C}_{6} \mathrm{H}_{5}$ & $\mathrm{H}$ & $\mathrm{H}$ & 2 & 0.227 & 6.64 \\
\hline A-22 & $\mathrm{H}$ & $\mathrm{H}$ & $\mathrm{C}_{6} \mathrm{H}_{5}$ & $\mathrm{H}$ & $\mathrm{H}$ & 3 & 0.233 & 6.63 \\
\hline A- 23 & $\mathrm{H}$ & $\mathrm{H}$ & $\mathrm{C}_{6} \mathrm{H}_{5}$ & $\mathrm{H}$ & $\mathrm{H}$ & 4 & 2.66 & 5.58 \\
\hline A- 24 & $\mathrm{H}$ & $\mathrm{H}$ & $\mathrm{C}_{6} \mathrm{H}_{5}$ & $\mathrm{H}$ & $\mathrm{H}$ & 5 & 2.49 & 5.60 \\
\hline
\end{tabular}

\section{Pharmacophore and atom based 3D QSAR modelling}

3D QSAR modelling methods are being gradually employed for lead discovery, optimization and understanding the interactions between the drug and the receptor molecules. The development of structureactivity correlation and 3D QSAR models were achieved using 'PHASE'v3.4 (Schrodinger, LLC, New York) [18]. Common pharmacophore hypothesis was produced using Phase module which initially involved clean-up of ligands and generation of conformers through the use of OPLS_2005 force field [19]. After the generation of conformers, sites were created which provided possible common pharmacophore features such as ADNHR; where A, D, N, H, R and P stands for hydrogen bond acceptor, hydrogen bond donor, negatively charged group, a hydrophobic group, an aromatic ring and positively charged group, respectively. PHASE correlated and categorized the activities of ligand molecules into active, moderately active and inactive molecules employing volume, vector, and site score. Furthermore, on the basis of the alignment of these molecules PHASE developed 3D pharmacophores as common feature hypotheses [20]. These pharmacophores were analyzed using survival, survival minus inactive and posthoc scoring techniques to determine best suitable common pharmacophore hypothesis. The high scored common pharmacophore hypothesis was selected for alignment and further 3D-QSAR studies. The leave one out (LOO) method was adopted to generate and validate an effective 3D-QSAR model. The suitability of the 3D-QSAR models was determined by analyzing the various parameters including regression coefficient $(>0.6)$, a minute standard deviation, elevated variance ratio, high stability score, low RMSE value and high Pearson R-value [19-21]. The appropriate hypothesis was selected in the Score Hypotheses step by selecting the different training and test sets, and visualizing the model results which provided fruitful outcomes to investigate the optimization of core structures [20,21].

\section{Docking method}

Molecular docking studies were accomplished using Glide v5.8 (Schrodinger, LLC, New York, NY) which involved three sequential steps as preparation of protein molecule, generation of receptor grid, docking of ligands with protein [22]. The protein preparation step involved the acquirement of crystallized HDAC protein structure from protein data bank (PDB ID: 4BKX and 5ICN) and preparation of protein using "protein preparation wizard" in Maestro wizard v9.3 (Schrodinger, LLC, New York). The protein preparation process further comprised of two steps-first is the preparation of protein and second is a refinement of protein structure. The preparation step involved the addition of missing hydrogen atoms and missing side chains to the protein molecule. In the refinement step, the minimization of the protein molecule was achieved with the help of OPLS_2005 force field [23, 24]. After the preparation of protein, the receptor grid was produced for the active site using grid-receptor generation program. The ligands were drawn employing Ligprep module and docked with the help of SP (standard precision) and XP (extra precision) docking methods. The 
protein-ligand binding affinities of Glide XP docking were analyzed novel scoring function GScore. The comparison of docking pose, coverage of contacts docked ligand with the co-crystallized structure, accuracy along with RSMD were the major parameter used for validation of molecular studies [25-28].

\section{E-pharmacophore hypothesis generation}

The e-pharmacophore basically involved the structural and energetic data to find out the contact scoring using the scoring option of Glide XP [29]. It is a combined approach of structure and ligand-based 3D-QSAR technique. The e-pharmacophore hypothesis was generated using Maestro 9.3 [30-32].

\section{RESULTS AND DISCUSSION}

\section{Pharmacophore and atom based 3D QSAR modelling}

For the development of 3D-QSAR, we have set the active and inactive edge of biological data at 7.15 and 6.50, respectively. For QSAR analysis, 24 compounds were taken as a data set and out of these, 17 and 7 compounds were allocated as training set and test set, respectively. These 24 molecules were clustered into active, moderately active and inactive based on their activity profile. The test compounds were selected as they really indicate the training set. The common pharmacophore hypotheses were developed using common pharmacophore identification methodology. The five featured pharmacophore hypotheses with a high value of survival score, the capability to express the complete binding space of molecules were selected and subjected to scoring function and top twelve common pharmacophore hypothesis (table 2) were selected for preparation of 3D QSAR model employing three PLS factors.

The AADRR.356 common pharmacophore hypothesis was considered for 3D QSAR model development. The fitness, robustness and statistical validity of AADRR.356 QSAR models were analyzed and validated by standard deviation of the regression (SD) 0.1262 , coefficient of determination $\left(\mathrm{R}^{2}\right)$ 0.9588, F statistic (F) 100.7, statistical significance (P) 2.985e-009, stability value- 0.2636 , rootmean-square error (RMSE) 0.1857, prediction coefficient $\left(\mathrm{Q}^{2}\right)$ 0.7261 and pearson-R-value 0.8552 (table 3). The fitness of AADRR.356 Common pharmacophore hypothesis was expressed in fig. 2 and table 4 along with observed and predicted activity.

Table 2: Scoring results of the different hypotheses generated for pyrazole-based SAHA analogs

\begin{tabular}{|c|c|c|c|c|c|c|c|c|}
\hline ID & Survival & Survival-inactive & Post-hoc & Site & Vector & Volume & Selectivity & Matches \\
\hline ADDRR.848 & 3.651 & 1.3 & 3.651 & 0.93 & 0.998 & 0.719 & 1.653 & 5 \\
\hline AADDR.1255 & 3.651 & 1.402 & 3.651 & 0.93 & 0.998 & 0.719 & 1.467 & 5 \\
\hline ADHRR.411 & 3.631 & 1.281 & 3.631 & 0.89 & 0.998 & 0.74 & 1.814 & 5 \\
\hline AADHR.1407 & 3.621 & 1.459 & 3.621 & 0.93 & 0.98 & 0.707 & 1.556 & 5 \\
\hline ADDHR.680 & 3.62 & 1.372 & 3.621 & 0.95 & 0.989 & 0.678 & 1.759 & 5 \\
\hline AAAHR.553 & 3.595 & 1.152 & 3.595 & 0.92 & 0.99 & 0.685 & 1.557 & 5 \\
\hline DDHRR.590 & 3.565 & 1.225 & 3.565 & 0.88 & 0.977 & 0.703 & 2.145 & 5 \\
\hline AAHRR.1185 & 3.52 & 1.231 & 3.52 & 0.83 & 0.99 & 0.698 & 1.785 & 5 \\
\hline AADDH.315 & 3.484 & 1.21 & 3.484 & 0.88 & 0.953 & 0.652 & 1.409 & 5 \\
\hline AAADH.396 & 3.461 & 1.052 & 3.461 & 0.86 & 0.942 & 0.654 & 1.272 & 5 \\
\hline AADRR.356 & 3.406 & 1.35 & 3.406 & 0.78 & 0.954 & 0.667 & 1.454 & 5 \\
\hline AAADR.427 & 3.396 & 1.228 & 3.396 & 0.78 & 0.934 & 0.681 & 1.322 & 5 \\
\hline
\end{tabular}

Table 3: Statistical results of a 3D-QSAR model developed using AADRR.356 common pharmacophore hypothesis for PLS factor 3 of pyrazole-based SAHA analogs

\begin{tabular}{|c|c|c|c|c|c|c|c|c|c|}
\hline ID & PLS Factor & SD & $\mathbf{R}^{2}$ & $\mathbf{F}$ & $\mathbf{P}$ & Stability & RMSE & $\mathbf{Q}^{2}$ & Pearson-R \\
\hline \multirow{3}{*}{ AADRR.356 } & 1 & 0.337 & 0.6606 & 29.2 & $7.318 \mathrm{e}-005$ & 0.2618 & 0.2518 & 0.4964 & 0.7175 \\
\hline & 2 & 0.2078 & 0.8796 & 51.2 & $3.657 \mathrm{e}-007$ & -0.2001 & 0.2702 & 0.4203 & 0.662 \\
\hline & 3 & 0.1262 & 0.9588 & 100.7 & $2.985 \mathrm{e}-009$ & -0.2636 & 0.1857 & 0.7261 & 0.8552 \\
\hline
\end{tabular}

(a)

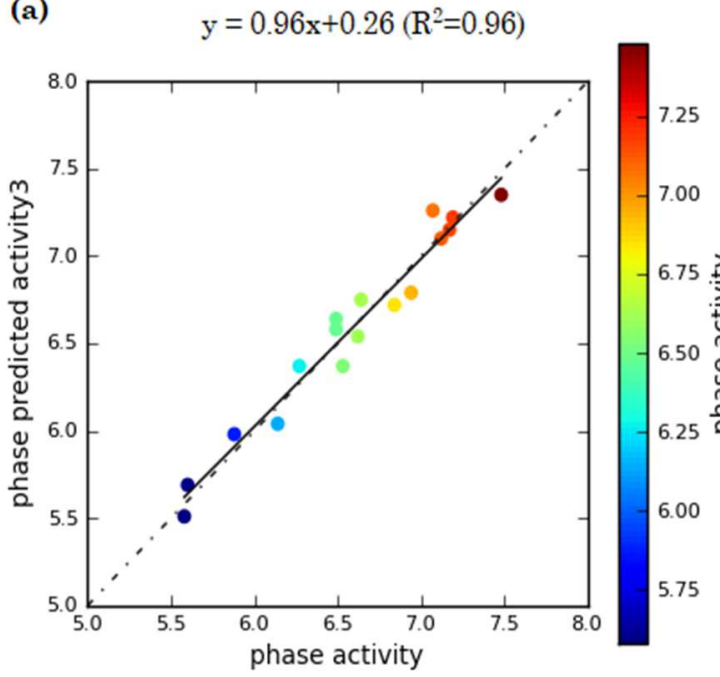

(b)

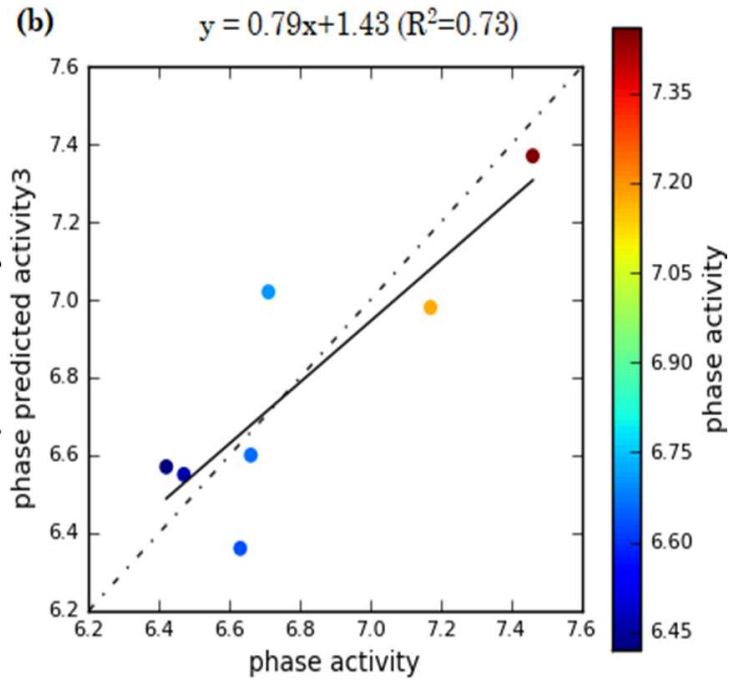

Fig. 2: The plot of observed activity versus predicted activity for 3D-QSAR model generated using common pharmacophore hypothesis: AADRR.356 (a) training set (b) test set. The graphical representations were obtained using Schrödinger software module 
(a)

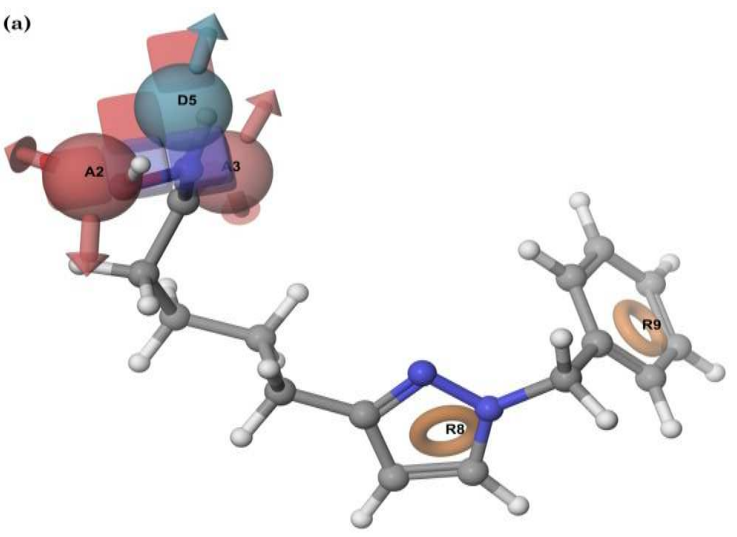

(b)

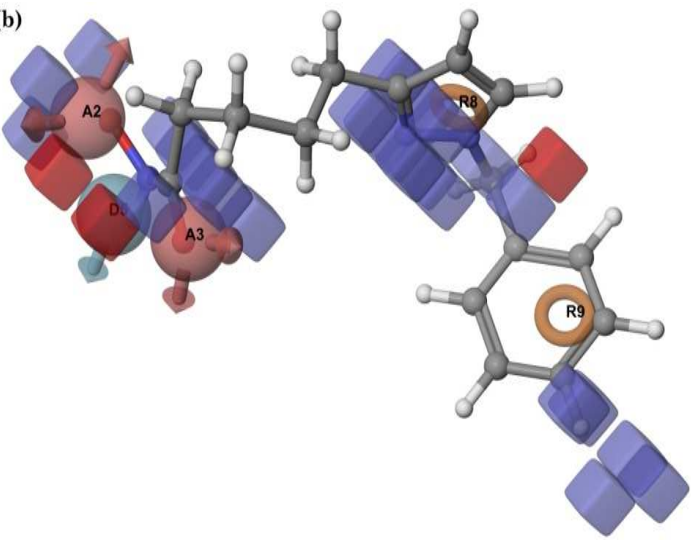

(c)

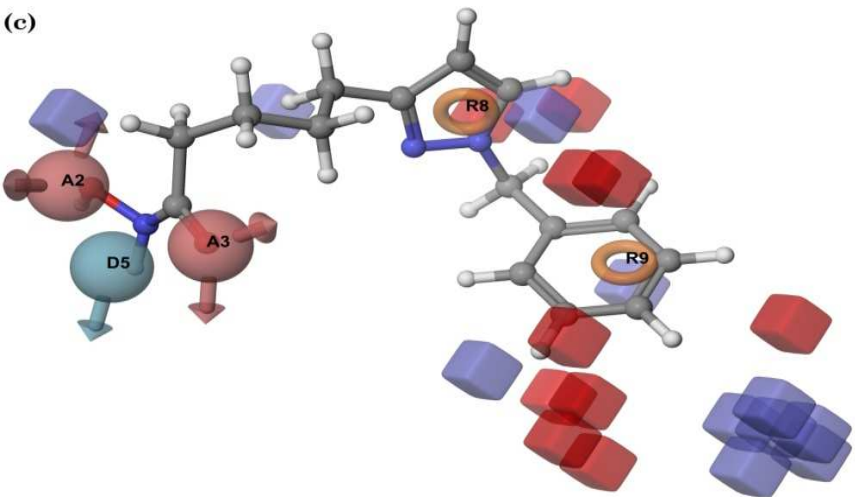

Fig. 3: Cubic pictorial representation of 3-D QSAR model based on ligand 1 (training set) for AADRR.356 common pharmacophore hypothesis (a) hydrogen bond donor features (b) hydrogen bond acceptor features (c) hydrophobic features. Blue colored cubes indicated favorable regions, while red colored cubes indicated unfavorable region for HDAC1 inhibitory activity. The graphical representations were obtained using Schrödinger software module

Table 4: Pyrazole based SAHA analogs with predicted activity and fitness score

\begin{tabular}{|c|c|c|c|c|c|}
\hline Ligand name & QSAR Set & Activity & Predicted activity & Pharm set & Fitness \\
\hline 1 & training & 6.49 & 6.64 & Inactive & 2.19 \\
\hline 2 & training & 5.88 & 5.98 & Inactive & 2.08 \\
\hline 3 & training & 6.49 & 6.58 & inactive & 2.19 \\
\hline 4 & test & 6.66 & 6.60 & & 2.19 \\
\hline 5 & training & 6.62 & 6.54 & & 2.34 \\
\hline 6 & test & 6.71 & 7.02 & & 2.44 \\
\hline 7 & training & 6.53 & 6.37 & & 2.26 \\
\hline 8 & test & 6.47 & 6.55 & inactive & 2.25 \\
\hline 9 & training & 7.17 & 7.15 & active & 2.53 \\
\hline 10 & training & 6.94 & 6.79 & & 2.14 \\
\hline 11 & training & 6.27 & 6.37 & inactive & 2.28 \\
\hline 12 & training & 7.48 & 7.35 & active & 2.36 \\
\hline 13 & training & 7.19 & 7.22 & active & 2.59 \\
\hline 14 & test & 6.42 & 6.57 & inactive & 2.3 \\
\hline 15 & test & 7.17 & 6.98 & active & 2.27 \\
\hline 16 & training & 7.07 & 7.26 & & 2.69 \\
\hline 17 & training & 7.12 & 7.10 & & 2.35 \\
\hline 18 & test & 7.46 & 7.37 & active & 3 \\
\hline 19 & training & 6.84 & 6.72 & & 1.83 \\
\hline 20 & training & 6.14 & 6.04 & inactive & 2.1 \\
\hline 21 & training & 6.64 & 6.75 & & 1.97 \\
\hline 22 & test & 6.63 & 6.36 & & 1.53 \\
\hline 23 & training & 5.58 & 5.51 & inactive & 1.94 \\
\hline 24 & training & 5.6 & 5.69 & inactive & 1.19 \\
\hline
\end{tabular}

The evaluation of generated 3D-QSAR models was based on the various features, i.e., hydrogen bond donor, hydrogen bond acceptor and hydrophobic character. For the visualization of 3D-QSAR, the favourable and unfavourable features for biological activity has been presented in cube form as depicted in fig. 3(a,b,c). The blue cubes indicated favorable features, while red cube indicated unfavourable features. In the development of 3D-QSAR model, ligand 1 was selected as a training set to the best representation of hydrogen donor, hydrogen bond acceptor, hydrophobic and electronic characteristic predictions features as depicted in fig. 3(a,b,c). In AADRR.356 common pharmacophore hypothesis, the substitution of hydrogen bond donor around the blue region at A3 and A2 position 
favored the HDAC1 inhibition activity, while H-bond donor around the red region at D5 position unfavored the HDAC1 inhibition activity (fig. 3a). Hydrogen bond acceptor or electron withdrawing group around the blue region at A2, A3, N atoms of pyrazole nucleus of $\mathrm{R} 8$ ring and $\mathrm{R}_{4}$ position of $\mathrm{R} 9$ ring favored the HDAC1 inhibitory activity (fig. $3 \mathrm{~b}$ ). The replacement of hydrophobic groups near the blue region at $\mathrm{R}_{4}$ position i.e., substitution of $\mathrm{C}_{6} \mathrm{H}_{5} \mathrm{NH}, \mathrm{C}_{6} \mathrm{H}_{5}, \mathrm{C}_{6} \mathrm{H}_{5} \mathrm{O}$, $\mathrm{C}_{6} \mathrm{H}_{5} \mathrm{CH}_{2} \mathrm{O}$ groups at $\mathrm{R}_{4}$ increased the HDAC1 inhibitory activity, while the substitution around the red region at $R_{3}$ and $R_{2}$ positions resulted in decreased HDAC1 inhibitory activity.

\section{Molecular docking study}

All structures were docked with HDAC1 proteins (PDB ID: 4BKX and 5ICN) for examining the binding mode of compounds for HDAC inhibitory activity. The carbonyl oxygen of hydroxamic acid interacted with zinc atom and NH group interacted with GLY 149 in both the proteins in a similar manner. Compound 1 showed critical hydrophobic interaction with TYR 204 in 5ICN protein [fig. 4(c,d)] while showed hydrophobic interactions with HIE 28, PHE 150 and PHE 205 amino acids in $4 \mathrm{BKX}$ protein as reported in various studies [fig. 4(a,b)] [33-35].

\section{E-pharmacophore studies}

The e-pharmacophoric features were developed for pyrazole analogues against 4BKX and 5ICN HDAC1 proteins. We have predicted for seven pharmacophoric sites, but four pharmacophoric sites were scored against $4 \mathrm{BKX}$ while five pharmacophoric features were scored against 5ICN. The pharmacophoric scores and generated corresponding features are described in table 5. These scores of pharmacophoric features revealed that hydrogen bonding of compounds with the receptor at A3 and D5 in both the proteins are important pharmacophores, While R8 in 4BKX based epharmacophore and R7 and R8 in 5ICN based e-pharmacophores are essential for the hydrophobic environment (fig. 5).

Table 5: Scores of e-pharmacophoric features applying glide XP docking

\begin{tabular}{llll}
\hline Protein PDB ID & Feature label & Score & Score source \\
\hline 4BKX & A3 & -0.67 & H-bond \\
& D5 & -0.62 & H-bond \\
& H6 & -0.17 & Phob En \\
5ICN & R8 & -0.77 & Ring Chemscore Hphobe \\
& H6 & -0.29 & Phob En \\
& A3 & -0.24 & H-Bond \\
& D5 & -0.15 & Ring Chemscore Hphobe \\
& R7 & -0.82 & Ring Chemscore Hphobe \\
\hline
\end{tabular}
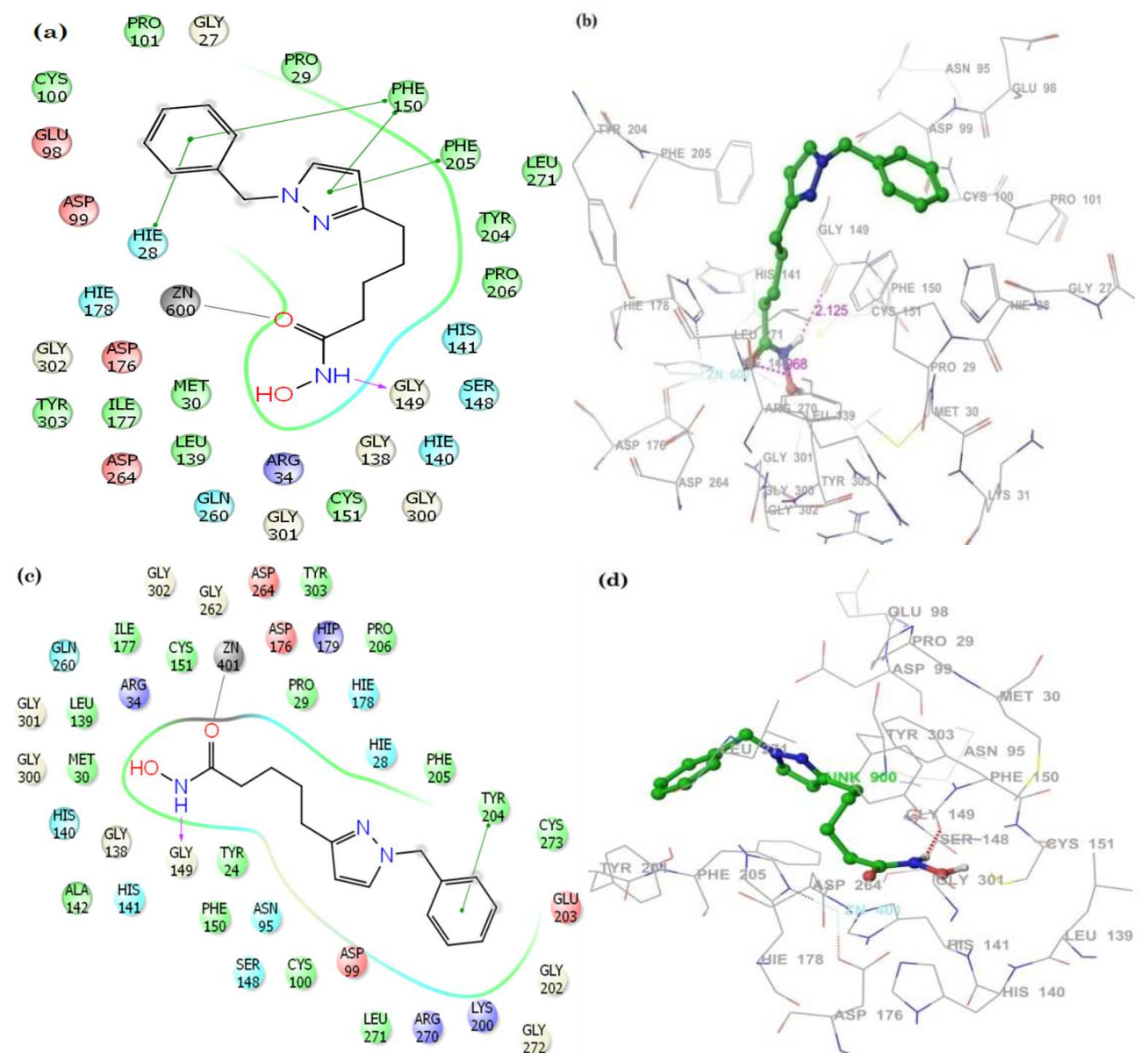

Fig. 4: Docking of compound 1 on HDAC1 proteins (a) 2D binding representation of the compound 1 on HDAC1 (PDB ID: 4BKX) (b) Docked pose of compound 1 (green) with HDAC1 protein (PDB ID: 4BKX) (c) 2D binding representation of the compound 1 on HDAC1 (PDB ID: 5ICN) (d) Docked pose of compound 1 (green) with HDAC1 protein (PDB ID: 5ICN). Pink dotted lines indicate hydrogen binding. The graphical representations were obtained using Schrödinger software module 
(a)

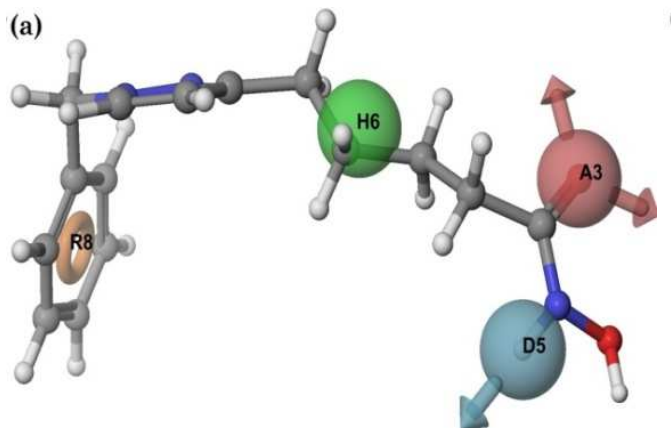

(b)

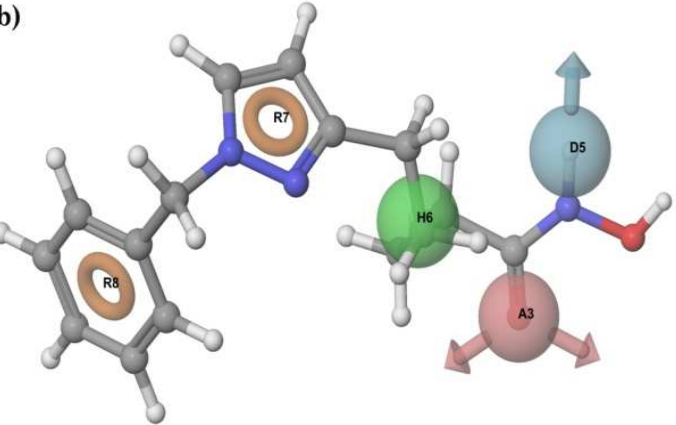

Fig. 5: Pharmacophoric features of pyrazole derivatives in (a) 4BKX (b) 5ICN HDAC1 proteins using the e-pharmacophore script. Hydrogen bond acceptor (A3 = pink and D5 = magenta), hydrophobic aromatic rings (R8 and R7 = orange) and Phab En (H6 = green). The graphical representations were obtained using Schrödinger software module

\section{CONCLUSION}

Ligand and structure-based computer-aided drug design strategies i.e., Pharmacophore and atom based 3D-QSAR modelling, molecular docking and energetic based pharmacophore mapping, were applied to establish the structure-activity correlation of pyrazole-based SAHA analogs. Pharmacophoric model was developed by Phase module and e-pharmacophore mapping on compound 1 . The pharmacophoric models were characterized by a set of points in 3D space, which correspond to a variety of chemical features which may assist non-covalent binding between the ligand molecule and its corresponding target receptor. The visualization of the 3D-QSAR model pointed out that the pyrazole nucleus played an important role in hydrophobic character in cap group responsible for recognition of active binding site in a protein molecule. Molecular docking studies indicated that all the pyrazole derivatives bind with HDAC1 proteins and the carbonyl oxygen of hydroxamic acid interacts with zinc atom and NH group interacts with GLY 149 in both the proteins in a similar manner. Compound $\mathbf{1}$ showed critical hydrophobic interaction with TYR 204 of 5ICN protein while showed interactions with HIE 28, PHE 150 and PHE 205 of 4BKX protein. It is anticipated that the results of these structure and ligand-based strategies could be employed for the precise design of novel pyrazole-based HDACi.

\section{ACKNOWLEDGEMENT}

One of the authors, Avineesh Singh is grateful to council of scientific and industrial research (CSIR), New Delhi, India for granting financial assistance in the form of a senior research fellowship (SRF). One of the authors Harish Rajak is highly indebted to university grants commission (UGC) New Delhi and department of science and technology-science and engineering research board (DST-SERB), New Delhi, India for granting financial support in the form of 'major research project' [Grant No. 40-275/2011 (SR)] and 'start-up grant for young scientist' [Grant No. SERB/IS-385/2013], respectively.

\section{AUTHORS CONTRIBUTIONS}

The research work is carried out by Avineesh Singh under the supervision of Harish Rajak.

\section{CONFLICT OF INTERESTS}

\section{Declared none}

\section{REFERENCES}

1. Drwal MN, Griffith R. Combination of ligand-and structurebased methods in virtual screening. Drug Disc Today Tech 2013;10:395-401.

2. Olivier S, Maria AM, Bruno OV. Combining ligand-and structure-based methods in drug design projects. Curr Comput Aided Drug Des 2008;4:250-8.

3. El-Zayat AA, Degen D, Drabek S, Clark GM, Pettit GR, Von Hoff DD. In vitro evaluation of the antineoplastic activity of combretastatin A-4, a natural product from combretum caffrum (arid shrub). Anticancer Drugs 1993;4:19-25.
4. Yuanita E, Pranowo HD, Jumina J, Mustofa M. Design of hydroxy xanthones derivatives as anticancer using quantitative structure-activity relationship. Asian J Pharm Clin Res 2016;9:180-5.

5. Juliet AM, Cn H, Aanandhi MV. Computational studies of purine derivative using multiforms of human polypeptides 1 as a target enzyme for anticancer agents. Asian J Pharm Clin Res 2017;10:292-6

6. Pradeep PS, Shrungesh Kumar TO, Prashantha N, Mahadevan KM. Synthesis, in vitro antibacterial, toxicity and molecular docking anticancer activity of novel N-[(2-chloroquinolin-3-yl) methylidene]-2-aniline schiff's bases. Int J Curr Pharm Res 2015;7:37-46.

7. Manal M, Chandrasekar MJ, Gomathi Priya J, Nanjan MJ. Inhibitors of histone deacetylase as antitumor agents: a critical review. Bioorg Chem 2016;67:18-42.

8. Rajak H, Singh A, Raghuwanshi K, Kumar R, Dewangan PK, Veerasamy $\mathrm{R}$, et al. A structural insight into hydroxamic acid based histone deacetylase inhibitors for the presence of anticancer activity. Curr Med Chem 2014;21:2642-64.

9. Chen JB, Chern TR, Wei TT, Chen CC, Lin JH, Fang JM. Design and synthesis of dual-action inhibitors targeting histone deacetylases and 3-hydroxy-3-methylglutaryl coenzyme a reductase for cancer treatment. J Med Chem 2013;56:3645-55.

10. Guerrant W, Patil V, Canzoneri JC, Oyelere AK. Dual targeting of histone deacetylase and topoisomerase II with novel bifunctional inhibitors. J Med Chem 2012;55:1465-77.

11. Mwakwari SC, Guerrant W, Patil V, Khan SI, Tekwani BL, Gurard-Levin ZA, et al. Non-peptide macrocyclic histone deacetylase inhibitors derived from tricyclic ketolide skeleton. J Med Chem 2010;53:6100-11.

12. Canzoneri JC, Chen PC, Oyelere AK. Design and synthesis of novel histone deacetylase inhibitor derived from nuclear localization signal peptide. Bioorg Med Chem Lett 2009;19:6588-90.

13. Ding C, Chen S, Zhang C, Hu G, Zhang W, Li L, et al. Synthesis and investigation of novel 6-(1,2,3-triazol-4-yl)-4aminoquinoline derivatives possessing hydroxamic acid moiety for cancer therapy. Bioorg Med Chem 2017;25:27-37.

14. Guerrant W, Patil V, Canzoneri JC, Yao LP, Hood R, Oyelere AK. Dual-acting histone deacetylase-topoisomerase I inhibitors. Bioorg Med Chem Lett 2013;23:3283-7.

15. Sun Q, Yao Y, Liu C, Li H, Yao H, Xue X, et al. Design, synthesis, and biological evaluation of novel histone deacetylase 1 inhibitors through click chemistry. Bioorg Med Chem Lett 2013;23:3295-9.

16. Yao Y, Liao C, Li Z, Wang Z, Sun Q, Liu C, et al. Design, synthesis, and biological evaluation of 1, 3-disubstituted-pyrazole derivatives as new class I and IIb histone deacetylase inhibitors. Eur J Med Chem 2014;86:639-52.

17. Ligprep, version 2.5, Schrödinger, LLC, New York, NY; 2012.

18. Phase, version 3.4, Schrödinger, LLC, New York, NY; 2012.

19. Watts KS, Dalal P, Murphy RB, Sherman WR, Friesner A, Shelley JC. Conf gen: a conformational search method for efficient generation of bioactive conformers. J Chem Inf Model 2010;50:534-46. 
20. Dixon SL, Smondyrev AM, Knoll EH, Rao SN, Shaw DE, Friesner RA. PHASE: a new engine for pharmacophore perception, 3D QSAR model development, and 3D database screening: 1. methodology and preliminary results. J Comput-Aided Mol Des 2006;19:647-67.

21. Golbraikh A, Tropsha A. Predictive QSAR modelling based on diversity sampling of experimental datasets for the training and test set selection. J Comput Aided Mol Des 2002;16:357-69.

22. Glide, version 5.8, Schrödinger, LLC, New York, NY; 2012.

23. Protein preparation wizard Schrödinger, LLC, New York, NY; 2012.

24. Jorgensen WL, Maxwell DS, Tirado-Rives J. Development and testing of the OPLS all-atom force field on the conformational energetics of organic liquids. J Am Chem Soc 1996;118:1122536.

25. Li X, Li Y, Cheng T, Liu Z, Wang R. Evaluation of the performance of four molecular docking programs on a diverse set of protein-ligand complexes. J Comput Chem 2010;31:210925.

26. Cross JB, Thompson DC, Rai BK, Baber JC, Fan KY, Hu Y, et al. Comparison of several molecular docking programs: pose prediction and virtual screening accuracy. J Chem Inf Model 2009;49:1455-74.

27. Zhou Z, Felts AK, Friesner RA, Levy RM. Comparative performance of several flexible docking programs and scoring functions: enrichment studies for a diverse set of pharmaceutically relevant targets. J Chem Inf Model 2007;47:1599-608.
28. Friesner RA, Murphy RB, Repasky MP, Frye LL, Greenwood JR, Halgren TA, et al. Extra precision glide: docking and scoring incorporating a model of hydrophobic enclosure for proteinligand complexes. J Med Chem 2006;49:6177-96.

29. Salam NK, Nuti R, Sherman W. Novel method for generating structure-based pharmacophores using energetic analysis. J Chem Inf Model 2009;49:2356-68.

30. Lokwani D, Shah R, Mokale S, Shastry P, Shinde D. Development of energetic pharmacophore for the designing of 1,2,3,4tetrahydropyrimidine derivatives as selective cyclooxygenase2 inhibitors. J Comput Aided Mol Des 2012;26:267-77.

31. Singh KD, Kirubakaran P, Nagarajan S, Sakkiah S, Muthusamy K, Velmurgan D, et al. Homology modelling, molecular dynamics, e-pharmacophore mapping and docking study of chikungunya virus nsP2 protease. J Mol Model 2012;18:39-51.

32. Loving K, Salam NK, Woody S. Energetic analysis of fragment docking and application to structure-based pharmacophore hypothesis generation. J Comput Aid Mol Des 2009;23:541-54.

33. Wu R, Lu Z, Cao Z, Zhang Y. Zinc chelation with hydroxamate in histone deacetylases modulated by water access to the linker binding channel. J Am Chem Soc 2011;133:6110-3.

34. Chen Y, Li H, Tang W, Zhu C, Jiang Y, Zou J, et al. 3D-QSAR studies of HDACs inhibitors using pharmacophore-based alignment. Eur J Med Chem 2009;44:2868-76.

35. Ononye SN, Van Heyst MD, Oblak EZ, Zhou W, Ammar M, Anderson AC, et al. Tropolones as lead-like natural products: the development of potent and selective histone deacetylase inhibitors. ACS Med Chem Lett 2013;4:757-61. 